\title{
Autoimmune Thyroiditis and Glomerulopathies
}

\author{
Domenico Santoro $^{1 *}$, Carmela Vadalà ${ }^{1}$, Rossella Siligato $^{1}$, Michele Buemi ${ }^{1}$ \\ and Salvatore Benvenga ${ }^{2}$ \\ ${ }^{1}$ Unit of Nephrology and Dialysis, Department of Clinical and Experimental Medicine, University of Messina, Messina, Italy, \\ ${ }^{2}$ Unit of Endocrinology, Department of Clinical and Experimental Medicine, University of Messina, Messina, Italy
}

\section{OPEN ACCESS}

Edited by:

Rauf Latif,

Icahn School of Medicine at Mount Sinai, United States

Reviewed by: Laura Gragnani, University of Florence, Italy Silvia Martina Ferrari, University of Pisa, Italy

*Correspondence: Domenico Santoro santisi@hotmail.com

Specialty section: This article was submitted to Thyroid Endocrinology, a section of the journal Frontiers in Endocrinology

Received: 08 March 2017

Accepted: 16 May 2017

Published: 02 June 2017

Citation:

Santoro $D$, Vadalà $C$, Siligato $R$, Buemi M and Benvenga S (2017)

Autoimmune Thyroiditis and Glomerulopathies.

Front. Endocrinol. 8:119. doi: 10.3389/fendo.2017.00119
Autoimmune thyroiditis (AIT) is generally associated with hypothyroidism. It affects $~ 2 \%$ of the female population and $0.2 \%$ of the male population. The evidence of thyroid function- and thyroid autoantibody-unrelated microproteinuria in almost half of patients with AIT and sometimes heavy proteinuria as in the nephrotic syndrome point to a link of AIT with renal disease. The most common renal diseases observed in AIT are membranous nephropathy, membranoproliferative glomerulonephritis, minimal change disease, IgA nephropathy, focal segmental glomerulosclerosis, antineutrophil cytoplasmic autoantibody (ANCA) vasculitis, and amyloidosis. Different hypotheses have been put forward regarding the relationship between AIT and glomerulopathies, and several potential mechanisms for this association have been considered. Glomerular deposition of immunocomplexes of thyroglobulin and autoantibodies as well as the impaired immune tolerance for megalin (a thyrotropin-regulated glycoprotein expressed on thyroid cells) are the most probable mechanisms. Cross-reactivity between antigens in the setting of genetic predisposition has been considered as a potential mechanism that links the described association between ANCA vasculitis and AIT.

Keywords: thyroiditis, Hashimoto, glomerulonephritis, membranous glomerulopathy, vasculitis

\section{INTRODUCTION}

Hashimoto's thyroiditis is the leading form of autoimmune thyroiditis (AIT), which is the most prevalent autoimmune disorder and the most common cause of hypothyroidism, excluding iodine insufficiency. It affects $\sim 2 \%$ of the female population and $0.2 \%$ of the male population (1). This condition is well known to be associated with other autoimmune diseases, the most common of which are chronic autoimmune gastritis, vitiligo, rheumatoid arthritis, polymyalgia rheumatica, celiac disease, type 1 diabetes, Sjögren's syndrome, systemic lupus erythematosus (SLE), multiple sclerosis, and sarcoidosis (2). Also glomerular disease may be related to autoimmune disease with several mechanisms.

\section{THE EFFECTS OF THYROID HORMONES ON KIDNEY}

Thyroid hormone influence on kidney is mediated by its effect on the cardiovascular system and, consequently, by its effect on renal blood flow. Hypothyroidism initially decreases peripheral vascular resistance and blood pressure and subsequently activates the renin-angiotensin-aldosterone system, which increases tubular sodium reabsorption. As a consequence, cardiac preload and vascular resistance raise, resulting in increased diastolic blood pressure and cardiac afterload (3). Renin gene expression is also regulated by circulating levels of free triiodothyronine (FT3) and free 
thyroxine (FT4) through beta-adrenergic activation; accordingly, the reduced sensitivity to beta-adrenergic stimulus occurring in hypothyroidism can cooperate with other hemodynamic abnormalities decreasing renin release $(4,5)$. The resulting negative inotropic effect on the heart, as well as the altered equilibrium between the reduced expression of vasodilators such as vascular endothelial growth factor or insulin-like growth factor-1, can lead to further renal vasoconstriction. Other consequences of thyroid hormone deficiency include lower secretion of atrial natriuretic factor and erythropoietin, therefore reducing further blood volume (6). Glomerular filtration rate (GFR) can thus decrease by up to $40 \%$, with subsequent elevation of serum creatinine, both indices being directly proportional to circulating TSH levels (and therefore directly proportional to the extent of thyroid failure) independent of other confounding factors such as age, sex, body mass index, or comorbidities. Thyroid hormone replacement in patients with overt or subclinical hypothyroidism restores renal function (4, 7-9).

Experimental models of hypothyroid mice show kidney hypotrophy and altered glomerular structure (6). Salomon and colleagues studied the histopathology of renal lesions in a group of seven patients with hypothyroidism of both primary and secondary etiology (10). They discovered a common pattern in the renal biopsies from all seven patients, which was directly proportional to the duration of disease (10). Electron microscopy highlighted the thickening of both glomerular and tubular basement membranes, due in part to widening of the dense layer (lamina densa) and in part to considerable enlargement of the inner light layer (lamina rara interna); mesangial matrix was increased. Glomerular cells (epithelial, endothelial, and mesangial) presented a variety of osmiophilic inclusions, most of them containing lipid. Tubular cells contain similar inclusions and also homogenous protein reabsorption droplets (10).

Gao et al. (11) measured serum $\beta 2$-microglobulin, urine $\beta 2$ microglobulin, albumin, and immunoglobulins in 39 untreated AITD (28 with Graves' disease and 11 with Hashimoto's disease). Microproteinuria was found in $28.6 \%$ of patients with Graves' disease and in $45.5 \%$ with Hashimoto's disease. Serum $\beta 2$-microglobulin concentrations were significantly increased in Graves' disease compared with that of controls. They concluded that the renal lesions associated with AIT are present in both the glomerulus (leading to increased glomerular capillary permeability) and the tubulus.

Free triiodothyronine can also influence the expression of structural and regulatory proteins in renal tubuli, particularly $\mathrm{Na}^{+} / \mathrm{K}^{+}$ATPase and $\mathrm{Ca}^{2+}$ and $\mathrm{Na}^{+} / \mathrm{H}^{+}$exchanger, which have a reduced activity in animal models of long-term hypothyroidism (12). These animals also have increased urinary excretion of sodium and bicarbonate, and defective urinary acidification. Lower medullary hypertonicity results in impaired urinary concentrating ability. On the other hand, increased sensitivity to vasopressin can stimulate water reabsorption (13). Moreover, the filtrate overload caused by altered tubular reabsorption processes, as well as the dysregulation of chloride channels $\mathrm{ClC}-2$, are responsible for the activation of tubuloglomerular feedback, which has important effects on GFR (14). Another important feature of hypothyroid murine models was the increased vascular calcification related to the lower expression of the matrix Gla protein, which physiologically exerts a protective role on vascular calcification (15).

\section{MECHANISMS OF AUTOIMMUNITY IN KIDNEY DISEASE}

Kidney can be the victim of autoimmune processes through several mechanisms. Autoantibodies can damage glomeruli either targeting specific antigens as in membranous glomerulonephritis (16) and in anti-glomerular basement membrane (GBM) nephropathy (17), or being trapped through the filtration barrier as in antineutrophil cytoplasmic autoantibody (ANCA) vasculitis (18) or IgA nephropathy (19). Pathophysiology of renal impairment in the course of SLE is characterized by both events, because antiDNA antibodies are located in capillary membranes and mesangial areas of glomeruli and because they cross-react with $\alpha$-actinin and glycosaminoglycans on mesangial cells (20). All these immune complexes alter the structure of basement membrane, podocyte function, and activate the classical pathway of complement system, which exacerbate the inflammatory process due to chemotactic factors $\mathrm{C} 3 \mathrm{a}$ and $\mathrm{C} 5 \mathrm{a}$. In addition, terminal pathway of complement worsens cell damage because of the cytolytic effect of C5b-9 complex (21). Finally, immune complexes stimulate infiltration of innate and specific immune cells, such as neutrophils, macrophages, natural killer (NK) cells, and T lymphocytes, which express receptors for constant fraction (FcR) $(22,23)$.

Natural killer cells have also a role in the pathogenesis of kidney damage as they produce interferon $\gamma$ (IFN $\gamma$ ) and activate peripheral macrophages first and, then, resident glomerular cells that are responsible of chronic processes $(24,25)$.

Kidney-resident dendritic cells secrete IL-23 to recruit both $\gamma \delta \mathrm{T}$ cells, a specific $\mathrm{T}$ subset with adaptive and innate features and a pro-inflammatory role consisting in regulatory $\mathrm{T}$ cells $\left(\mathrm{T}_{\mathrm{reg}}\right)$ inhibition, stimulation of B lymphocyte antibodies production and the secretion of cytokines (26). In particular, $\gamma \delta \mathrm{T}$ cells and double-negative $\mathrm{CD} 4^{-} \mathrm{CD} 8^{-} \mathrm{T}$ cells sustain production of IL-17, which is responsible for neutrophils recruitment. They, in turn, have a central role in damaging kidney through the programmed cell death of neutrophil extracellular traps (NETosis) and the production of reactive oxygen species that stimulate mesangial cell proliferation and cytotoxicity mechanisms (27-29). In addition, IL-17 promotes expression of C-C motif chemokine 20 (CCL20) on mesangial cells, that recruit $\mathrm{T}$ helper cells producing IL-17 $\left(\mathrm{T}_{\mathrm{H}} 17\right) . \mathrm{T}_{\mathrm{H}} 17$ are able to maintain kidney damage and promote B-cell activation through the secretion of IL-21 (30). Finally, $\mathrm{T}$ follicular helper cells, a subpopulation of $\mathrm{CD} 4^{+}$that is increased in autoimmune processes, act as stimulator of B cell differentiation into plasma cells (31-33).

$\mathrm{T}_{\mathrm{H}} 1$ lymphocytes and IFN $\gamma$ stimulate macrophage recruitment in SLE- and ANCA-associated vasculitis, as well as antiGBM nephropathy in experimental models. However, the role of $\mathrm{T}_{\mathrm{H}} 1$ lymphocytes in human autoimmune renal disease is not clearly defined yet (34-36). CD8 ${ }^{+} \mathrm{T}$ cells have a pathogenic role in ANCA-associated vasculitis, since they can produce both IFN $\gamma$ and tumor necrosis factor (37). The presence of $\mathrm{CD}^{+} \mathrm{T}$ cells is also correlated with poor prognosis (38). 
Regulatory T cells as well as NKT cells act as regulators of immune response and are reduced in autoimmune disease $(39,40)$.

\section{GLOMERULAR DISEASE RELATED TO AIT}

Glomerular involvement in patients with AIT can occur in $10-30 \%$ of cases (41). A retrospective study on 28 patients with Hashimoto's thyroiditis and hematuria, proteinuria, or renal impairment showed that the most common associated kidney diseases are membranous glomerulonephritis (20\%), focal segmental glomerulosclerosis (20\%), IgA nephropathy (15\%), chronic glomerulonephritis (15\%), minimal change disease (10\%), and amyloidosis (5\%). In $15 \%$ of the 28 patients, no specific diagnosis was made (42). Other case reports revealed the less frequent connection between AIT and membranoproliferative glomerulonephritis and ANCA vasculitis (43-47) (Figure 1).

Various hypotheses were considered to explain the underlying mechanism that links AIT to glomerular lesions and their variable presentation (Table $\mathbf{1}$ ).

The higher prevalence of membranous nephropathy (MN) suggests a plausible immunologic role of thyroid antigens, particularly thyroglobulin (TG) and thyroperoxidase (TPO). Both of them are released in the course of AIT and are found in subepithelial immune deposits, as part of the characteristic spikes of $\mathrm{MN}(47,48)$. At present, there are two possible mechanisms that can explain the immunologic role of thyroid antigens in the pathogenesis of $\mathrm{MN}$ : (1) in situ immune response against TG deposition at subepithelial level and (2) circulating immune complexes (TG-anti-TG) that can be trapped at subendothelial level due to increased glomerular permeability. As stated before, the pathogenicity of immune complexes in $\mathrm{MN}$ is related to their subepithelial localization, but how they could cross GBM remains unexplained. Most likely, immune complexes could dissociate in the subendothelial space and then they would reassemble on the subepithelial side. IgG4 is considered the main antibody subclass deposited in the course of idiopathic MN. Specific subclass of anti-TG and anti-TPO antibodies should be determined in patients with suspicious AIT-related glomerulopathy to distinguish between a clear diagnosis of idiopathic MN or a possible IgG4-mediated secondary form of MN. Moreover, IgG4 antibodies have low affinity for the antigen, which could explain the possible dissociation and reassociation of the IgG4 complexes through the GBM (49).

Other theories involve the mechanism of epitope spreading, a phenomenon that follows the primary immune response against specific epitopes. When the immunodominant response fails to clear the target, the immune system mounts a broader inflammatory response against different epitopes either on the same or on different molecules. Therefore, immune-mediated glomerular disease would be caused by a subset of autoantibodies directed toward epitopes of TG or TPO as well as epitopes of glomerular antigens. This phenomenon may be relevant to the pathogenesis of kidney disease, since in Heymann nephritis (a murine experimental model of membranous glomerulonephritis) the onset of proteinuria correlates with intramolecular epitope spreading (50). In addition, epitope spreading has already been demonstrated in experimental immunization with an immunogenic TG peptide, but has not been investigated in patients yet (51).

The experimental Heymann model also suggests megalin (gp330) as a possible immunologic target involved in the immunopathogenesis of glomerular injury during AIT. Megalin is a large glycoprotein receptor expressed on thyrocytes in a TSH-dependent manner, but it is also expressed on the renal proximal tubular cells (52). Megalin is a receptor that interacts with various intracellular adaptor proteins for intracellular trafficking and that functions cooperatively with other membrane molecules (52). Megalin is involved in the uptake of glomerularfiltered albumin and other molecules such as insulin, hemoglobin, vitamin D-binding protein, retinol-binding protein, and $\beta_{2}$-microglobulin. In addition, a number of toxic substances, such as glycated proteins (AGEs), myeloma light chain, and aminoglycosides, undergo megalin-mediated endocytosis, leading to cell damage (52). AIT could determine a rupture of immune tolerance toward this self-antigen, thus causing an immune response on podocytes.

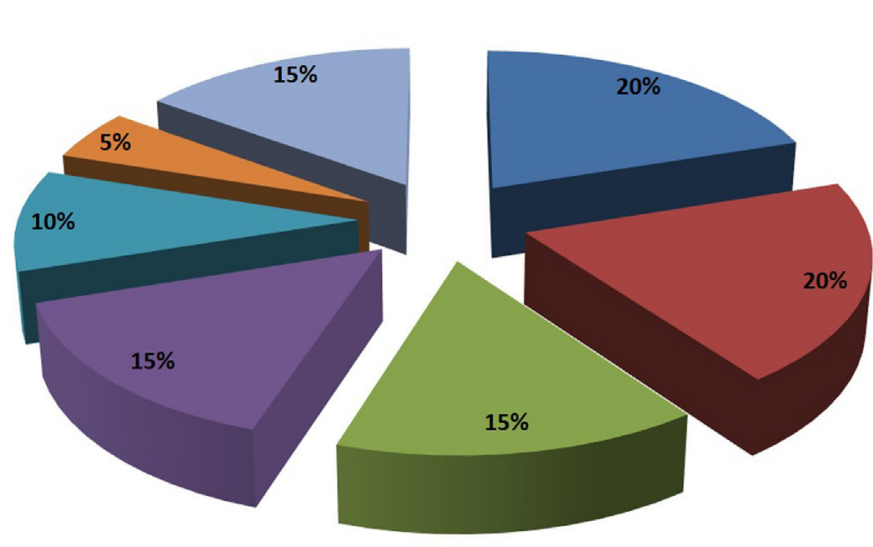

- Focal segmental glomerulonephritis

Membranous glomerulon ephritis

IgA nephropathy

— Chronic glomerulonephritis

- Minimal change disease

Amyloidosis

No specific diagnosis

FIGURE 1 | Glomerulopathies associated with HT. 
TABLE 1 | Mechanisms underlying the relationship between HT and kidney disease.

In situ immune response against thyroglobulin (TG) deposition at subepithelial level

Circulating TG-anti-TG complexes trapped at subendothelial level due to increased glomerular permeability

Megalin (gp330) as a possible immunologic target

Epitope spreading

Genetic predisposition and cross-reactivity between antigens

The relationship between AIT and ANCA vasculitis was shown by Lionaki and colleagues (53). In their case-control study, they demonstrated that when ANCA vasculitis was diagnosed, as many as $40 \%$ of women had thyroid disease. Among men, the prevalence of thyroid disease was lower. Patients with positive anamnesis for thyroid disease were more likely to have myeloperoxidase (MPO)-ANCA (86\%) than proteinase 3-ANCA (14\%) (53). Both genetic predisposition and cross-reactivity between antigens have been hypothesized as potential mechanisms for this association. A functional polymorphism in the protein tyrosine phosphatase gene, the PTPN22 620W allele has been recognized as a predisposing factor for several autoimmune disorders, including AITD, Wegener's granulomatosis, and ANCA positivity (54-56). PTPN22 is located on chromosome 1p13.3-13.1.10 and encodes an 807-amino acid protein that interacts with Csk, a tyrosine kinase that is involved in the intracellular signaling cascade following T-cell activation. A missense variation in the autoimmunity-predisposing allele results in gain of function that increases the threshold for T-cell receptor signaling (57). As in other multifactorial processes, one or more environmental triggers are necessary for the full development of the disease. Occupational exposures to factors such as silica (58) showed an association with ANCA vasculitis, while infections such as Yersinia enterocolitica or retroviruses have been postulated to participate in the pathogenesis of AITD (56). Eventually, crossreactivity between TPO and MPO may be another mechanism involved in the development of autoimmunity, due to the strong homology between amino acids 586-601 of TPO and amino acids 594-609 of MPO $(59,60)$.

Type 1 diabetes mellitus (DM1), a known autoimmune disease that can be present in $3-8 \%$ of patients with Hashimoto's

\section{REFERENCES}

1. Benvenga S, Trimarchi F. Changed presentation of Hashimoto's thyroiditis in North-Eastern Sicily. Thyroid (2008) 18(4):429-41. doi:10.1089/thy. 2007.0234

2. Fallahi P, Ferrari SM, Ruffilli I, Elia G, Biricotti M, Vita R, et al. The association of other autoimmune diseases in patients with autoimmune thyroiditis: review of the literature and report of a large series of patients. Autoimmun Rev (2016) 15(12):1125-8. doi:10.1016/j.autrev.2016.09.009

3. Klein I, Danzi S. Thyroid disease and the heart. Circulation (2007) 116:1725-35. doi:10.1161/CIRCULATIONAHA.106.678326

4. Iglesias P, Bajo MA, Selgas R, Díez JJ. Thyroid dysfunction and kidney disease: an update. Rev Endocr Metab Disord (2017) 18(1):131-44. doi:10.1007/ s11154-016-9395-7

5. Iglesias P, Díez JJ. Thyroid dysfunction and kidney disease. Eur J Endocrinol (2009) 160(4):503-15. doi:10.1530/EJE-08-0837 thyroiditis (61) and in 6-10\% of subjects with Graves' disease (62), is worth mentioning at this point. Benvenga et al. investigated the presence of serum antibodies directed against one or both thyroid hormones (THAbs), which are considered to be rare autoantibodies, in a cohort of $52 \mathrm{DM} 1$ patients both at baseline and after 6 years of follow-up (63). They found that serum THAb could be predictive for concurrent or subsequent DM1-related complications, including diabetic nephropathy. Patients already affected by nephropathy showed either T3IgG or T4IgM at baseline. T4IgM was associated with a high rate of retinopathy (67\%), nephropathy (50\%), and neuropathy (33\%). At tissue level (kidney, in this particular case), THAb may decrease the local availability of thyroid hormones, not much differently from the decreased tissue availability resulting from the decreased thyroid output of thyroid hormones. Clearly, this study (63) awaits confirmation by future investigations.

Finally, renal diseases presenting as nephrotic syndrome can lead to the onset or the aggravation of preexisting hypothyroidism. The urinary loss of both protein-unbound (free) and protein-bound thyroid hormones, with consequent decreased serum levels of T4, T3, FT4, FT3, and major carrier proteins (thyroxine-binding protein, transthyretin, and albumin), is directly proportional to proteinuria. The practical consequence of this urinary loss is the increased requirements of the daily $\mathrm{L}-\mathrm{T} 4$ replacement (64).

\section{CONCLUSION}

A relationship between AIT and glomerulonephritis does exist, but it requires further investigations in larger cohorts. A common pathogenesis may be considered, especially in patients with simultaneous appearance of glomerular and thyroid dysfunction. Monitoring kidney function should be considered as part of the follow-up of AIT patients, particularly of those with HT-related hypothyroidism.

\section{AUTHOR CONTRIBUTIONS}

Conceptualization: DS, CV, RS, and SB. Research literature: DS and MB. Methodology: DS and RS. Supervision: DS, MB, and SB. Writing original draft: DS, CV, and RS.

6. Vargas F, Moreno JM, Rodríguez-Gómez I, Wangensteen R, Osuna A, Alvarez-Guerra M, et al. Vascular and renal function in experimental thyroid disorders. Eur J Endocrinol (2006) 154(2):197-212. doi:10.1530/eje.1.02093

7. Sun MT, Hsiao FC, Su SC, Pei D, Hung YJ. Thyrotropin as an independent factor of renal function and chronic kidney disease in normoglycemic euthyroid adults. Endocr Res (2012) 3:110-6. doi:10.3109/07435800.2011.640374

8. Gopinath B, Harris DC, Wall JR, Kifley A, Mitchell P. Relationship between thyroid dysfunction and chronic kidney disease in community-dwelling older adults. Maturitas (2013) 2:159-64. doi:10.1016/j.maturitas.2013.03.009

9. Hataya Y, Igarashi S, Yamashita T, Komatsu Y. Thyroid hormone replacement therapy for primary hypothyroidism leads to significant improvement of renal function in chronic kidney disease patients. Clin Exp Nephrol (2013) 4:525-31. doi:10.1007/s10157-012-0727-y

10. Salomon MI, Di Scala V, Grishman E, Brener J, Churg J. Renal lesions in hypothyroidism: a study based on kidney biopsies. Metabolism (1967) 16:846-52. doi:10.1016/0026-0495(67)90186-2 
11. Gao YM, Gao Y, Lu G. The changes of urine protein and serum beta 2-microglobulin in autoimmune thyroid disease. Zhonghua Nei Ke Za Zhi (1994) 33:605-7.

12. Barlet C, Doucet A. Lack of stimulation of kidney Na-K-ATPase by thyroid hormones in long-term thyroidectomized rabbits. Pflugers Arch (1986) 4:428-31. doi:10.1007/BF00652629

13. Hanna FW, Scanlon MF. Hyponatraemia, hypothyroidism, and role of arginine-vasopressin. Lancet (1997) 9080:755-6. doi:10.1016/S0140-6736 (05)62563-9

14. van Hoek I, Daminet S. Interactions between thyroid and kidney function in pathological conditions of these organ systems: a review. Gen Comp Endocrinol (2009) 3:205-15. doi:10.1016/j.ygcen.2008.12.008

15. Sato Y, Nakamura R, Satoh M, Fujishita K, Mori S, Ishida S, et al. Thyroid hormone targets matrix Gla protein gene associated with vascular smooth muscle calcification. Circ Res (2005) 6:550-7. doi:10.1161/01.RES.0000181431. 04290.bd

16. Ronco P, Debiec H. Membranous nephropathy: a fairy tale for immunopathologists, nephrologists and patients. Mol Immunol (2015) 68:57-62. doi:10.1016/ j.molimm.2015.07.003

17. Cui Z, Zhao MH. Advances in human antiglomerular basement membrane disease. Nat Rev Nephrol (2011) 7:697-705. doi:10.1038/nrneph.2011.89

18. Jennette JC, Falk RJ. Pathogenesis of antineutrophil cytoplasmic autoantibody-mediated disease. Nat Rev Rheumatol (2014) 10:463-73. doi:10.1038/ nrrheum.2014.103

19. Holdsworth SR, Gan PY, Kitching AR. Biologics for the treatment of autoimmune renal diseases. Nat Rev Nephrol (2016) 12:217-31. doi:10.1038/ nrneph.2016.18

20. Zhao Z, Weinstein E, Tuzova M, Davidson A, Mundel P, Marambio P, et al. Cross-reactivity of human lupus anti-DNA antibodies with alpha-actinin and nephritogenic potential. Arthritis Rheum (2005) 52:522-30. doi:10.1002/ art. 20862

21. Suarez-Fueyo A, Bradley SJ, Klatzmann D, Tsokos GC. T cells and autoimmune kidney disease. Nat Rev Nephrol (2017) 13(6):329-43. doi:10.1038/ nrneph.2017.34

22. Kurts C, Panzer U, Anders HJ, Rees AJ. The immune system and kidney disease: basic concepts and clinical implications. Nat Rev Immunol (2013) 13:738-53. doi:10.1038/nri3523

23. Alexopoulos E, Seron D, Hartley RB, Nolasco F, Cameron JS. Immune mechanisms in idiopathic membranous nephropathy: the role of the interstitial infiltrates. Am J Kidney Dis (1989) 13:404-12. doi:10.1016/S0272-6386 (89)80024-1

24. Spada R, Rojas JM, Barber DF. Recent findings on the role of natural killer cells in the pathogenesis of systemic lupus erythematosus. J Leukoc Biol (2015) 98:479-87. doi:10.1189/jlb.4RU0315-081RR

25. Davidson A. What is damaging the kidney in lupus nephritis? Nat Rev Rheumatol (2016) 12:143-53. doi:10.1038/nrrheum.2015.159

26. Paul S, Shilpi C, Lal G. Role of gamma-delta $(\gamma \delta)$ T cells in autoimmunity. J Leukoc Biol (2015) 97:259-71. doi:10.1189/jlb.3RU0914-443R

27. Riol-Blanco L, Lazarevic V, Awasthi A, Mitsdoerffer M, Wilson BS, Croxford A, et al. IL-23 receptor regulates unconventional IL-17-producing $\mathrm{T}$ cells that control bacterial infections. J Immunol (2010) 184:1710-20. doi:10.4049/jimmunol.0902796

28. Mayadas TN, Rosetti F, Ernandez T, Sethi S. Neutrophils: game changers in glomerulonephritis? Trends Mol Med (2010) 16:368-78. doi:10.1016/j. molmed.2010.06.002

29. Gupta S, Kaplan MJ. The role of neutrophils and NETosis in autoimmune and renal diseases. Nat Rev Nephrol (2016) 12:402-13. doi:10.1038/nrneph.2016.71

30. Turner JE, Paust HJ, Steinmetz OM, Panzer U. The Th17 immune response in renal inflammation. Kidney Int (2010) 77:1070-5. doi:10.1038/ki.2010.102

31. Craft JE. Follicular helper T cells in immunity and systemic autoimmunity. Nat Rev Rheumatol (2012) 8:337-47. doi:10.1038/nrrheum.2012.58

32. Ueno H. T follicular helper cells in human autoimmunity. Curr Opin Immunol (2016) 43:24-31. doi:10.1016/j.coi.2016.08.003

33. Morita R, Schmitt N, Bentebibel SE, Ranganathan R, Bourdery L, Zurawski G, et al. Human blood CXCR5+CD4+ T cells are counterparts of T follicular cells and contain specific subsets that differentially support antibody secretion. Immunity (2011) 34:108-21. doi:10.1016/j.immuni.2010.12.012

34. Hünemörder S, Treder J, Ahrens S, Schumacher V, Paust HJ, Menter T, et al. TH1 and TH17 cells promote crescent formation in experimental autoimmune glomerulonephritis. J Pathol (2015) 237:62-71. doi:10.1002/ path.4559

35. Steinmetz OM, Turner JE, Paust HJ, Lindner M, Peters A, Heiss K, et al. CXCR3 mediates renal Th1 and Th17 immune response in murine lupus nephritis. J Immunol (2009) 183:4693-704. doi:10.4049/jimmunol.0802626

36. Yap DY, Lai KN. Pathogenesis of renal disease in systemic lupus erythematosus the role of autoantibodies and lymphocytes subset abnormalities. Int J Mol Sci (2015) 16:7917-31. doi:10.3390/ijms16047917

37. Chang J, Eggenhuizen P, O'Sullivan KM, Alikhan MA, Holdsworth SR, Ooi JD, et al. CD8+ T cells effect glomerular injury in experimental antimyeloperoxidase GN. J Am Soc Nephrol (2017) 28:47-55. doi:10.1681/ASN. 2015121356

38. McKinney EF, Lyons PA, Carr EJ, Hollis JL, Jayne DR, Willcocks LC, et al. A CD8+ T cell transcription signature predicts prognosis in autoimmune disease. Nat Med (2010) 16:586-91. doi:10.1038/nm.2130

39. Peterson RA. Regulatory T-cells: diverse phenotypes integral to immune homeostasis and suppression. Toxicol Pathol (2012) 40:186-204. doi:10.1177/ 0192623311430693

40. Chen J, Wu M, Wang J, Li X. Immunoregulation of NKT cells in systemic lupus erythematosus. J Immunol Res (2015) 2015:e206731. doi:10.1155/2015/206731

41. Ronco P, Debiec H. Pathophysiological lessons from rare associations of immunological disorders. Pediatr Nephrol (2009) 24(1):3-8. doi:10.1007/ s00467-008-1009-5

42. Koçak G, Huddam B, Azak A, Ortabozkoyun L, Duranay M. Coexistent findings of renal glomerular disease with Hashimoto's thyroiditis. Clin Endocrinol (2012) 76:759-62. doi:10.1111/j.1365-2265.2011.04302.x

43. Valentin M, Bueno B, Gutierrez E, Martinez A, Gonzalez E, Espejo B, et al. Membranoproliferative glomerulonephritis associated with autoimmune thyroiditis. Nefrologia (2004) 3:43-8.

44. Gurkan S, Dikman S, Saland MJ. A case of autoimmune thyroiditis and membranoproliferative glomerulonephritis. Pediatr Nephrol (2009) 24(1):193-7. doi:10.1007/s00467-007-0668-y

45. Kageyama Y, Hamaguchi K. Myeloperoxidase anti-neutrophil cytoplasmic antibody (MPO-ANCA)-positive microscopic polyarteritis (MPA) associated with Hashimoto's thyroiditis and increased serum rheumatoid factor. Clin Exp Nephrol (2000) 4:335-40. doi:10.1007/s101570070011

46. Thajudeen B, John SG, Ossai NO, Riaz IB, Bracamonte E, Sussman AN. Membranous nephropathy with crescents in a patient with Hashimoto's thyroiditis: a case report. Medicine (2014) 93(8):e63. doi:10.1097/MD.0000000000000063

47. Shima Y, Nakanishi K, Togawa H, Obana M, Sako M, Miyawaki M, et al. Membranous nephropathy associated with thyroid-peroxidase antigen. Pediatr Nephrol (2009) 24(3):605-8. doi:10.1007/s00467-008-0973-0

48. Jordan SC, Buckingham B, Sakai R, Olson D. Studies of immune-complex glomerulonephritis mediated by human thyroglobulin. N Engl J Med (1981) 304:1212-5. doi:10.1056/NEJM198105143042006

49. Oliveira DB. Membranous nephropathy: an IgG4-mediated disease. Lancet (1998) 351:670-1. doi:10.1016/S0140-6736(97)04122-6

50. Shah P, Tramontano A, Makker SP. Intramolecular spreading in Heymann nephritis. J Am Soc Nephrol (2007) 18:3060-6. doi:10.1681/ASN.2007030342

51. Thrasyvoulides A, Lymberi P. Evidence for intramolecular B-cell epitope spreading during experimental immunization with an immunogenic thyroglobulin peptide. Clin Exp Immunol (2003) 132:401-7. doi:10.1046/j. 1365-2249.2003.02162.x

52. Christensen EI, Birn H, Storm T, Weyer K, Nielsen R. Endocytic receptors in the renal proximal tubule. Physiology (Bethesda) (2012) 27(4):223-36. doi:10.1152/physiol.00022.2012

53. Lionaki S, Hogan SL, Falk RJ, Joy MS, Chin H, Jennette CE, et al. Association between thyroid disease and its treatment with ANCA small-vessel vasculitis: a case-control study. Nephrol Dial Transplant (2007) 22:3508-15. doi:10.1093/ ndt/gfm493

54. Brand O, Gough S, Heward J. HLA, CTLA-4 and PTPN22: the shared genetic master-key to autoimmunity? Expert Rev Mol Med (2005) 7:1-15. doi:10.1017/ S1462399405009981

55. Mustelin T. Are other protein tyrosine phosphatases than PTPN22 associated with autoimmunity? Semin Immunol (2006) 18:254-60. doi:10.1016/j. smim.2006.03.013

56. Corapçioğlu D, Tonyukuk V, Kiyan M, Yilmaz AE, Emral R, Kamel N, et al. Relationship between thyroid autoimmunity and Yersinia enterocolitica antibodies. Thyroid (2002) 12:613-7. doi:10.1089/105072502320288483 
57. Martorana D, Maritati F, Malerba G, Bonatti F, Alberici F, Oliva E, et al. PTPN22 R620W polymorphism in the ANCA-associated vasculitides. Rheumatology (Oxford) (2012) 51:805-12. doi:10.1093/rheumatology/ ker446

58. Hogan SL, Cooper GC, Savitz DA, Nylander-French LA, Parks CG, Chin $\mathrm{H}$, et al. Association of silica exposure with ANCA-associated glomerulonephritis: a population-based case-control study in the southeastern United States. Clin J Am Soc Nephrol (2007) 2:290-9. doi:10.2215/ CJN.03501006

59. Hobby P, Gardas A, Radomski R, McGregor AM, Banga JP, Sutton BJ. Identification of an immunodominant region recognized by human autoantibodies in a three-dimensional model of thyroid peroxidase. Endocrinology (2000) 141:2018-26. doi:10.1210/endo.141.6.7506

60. Haapala AM, Hyöty H, Parkkonen P, Mustonen J, Soppi E. Antibody reactivity against thyroid peroxidase and myeloperoxidase in autoimmune thyroiditis and systemic vasculitis. Scand J Immunol (1997) 46:78-85. doi:10.1046/j.13653083.1997.d01-90.x

61. Volpé R. Auto-immunity in thyroid disease. Monographs on Endocrinology: Auto-Immunity in the Endocrine System. Berlin, Heidelberg, New York: Springer-Verlag (1981). p. 19-111.
62. Van den Driessche A, Eenkhoorn V, Van Gaal L, De Block C. Type 1 diabetes and autoimmune polyglandular syndrome: a clinical review. Neth J Med (2009) 67:376-87.

63. Benvenga S, Pintaudi B, Vita R, Di Vieste G, Di Benedetto A. Serum thyroid hormone autoantibodies in type 1 diabetes mellitus. J Clin Endocrinol Metab (2015) 100(5):1870-8. doi:10.1210/jc.2014-3950

64. Benvenga S, Vita R, Di Bari F, Fallahi P, Antonelli A. Do not forget nephrotic syndrome as a cause of increased requirement of levothyroxine replacement therapy. Eur Thyroid J (2015) 4(2):138-42. doi:10.1159/000381310

Conflict of Interest Statement: The authors declare that the research was conducted in the absence of any commercial or financial relationships that could be construed as a potential conflict of interest.

Copyright $\odot 2017$ Santoro, Vadalà, Siligato, Buemi and Benvenga. This is an openaccess article distributed under the terms of the Creative Commons Attribution License (CC BY). The use, distribution or reproduction in other forums is permitted, provided the original author(s) or licensor are credited and that the original publication in this journal is cited, in accordance with accepted academic practice. No use, distribution or reproduction is permitted which does not comply with these terms. 